Supporting Information

\title{
Improving Performance of Organic-Silicon Heterojunction Solar Cells Based on Textured Surface via Acid Processing
}

\author{
Xiaowan Dai $i^{a}$ Tao Chen ${ }^{a}$ Hongkun Cai ${ }^{b^{*}}$ Hongbin Wen ${ }^{b}$ Yun Sun ${ }^{a}$
}

a Institute of Photo-electronic Thin Film Devices and Technology, Nankai

University, Tianjin, China,300071

b Department of Electronic Science and Engineering, College of Electronic Information and Optical Engineering, Nankai University, Tianjin, China,300071

Hongkun Cai, E-mail: caihongkun@nankai.edu.cn 


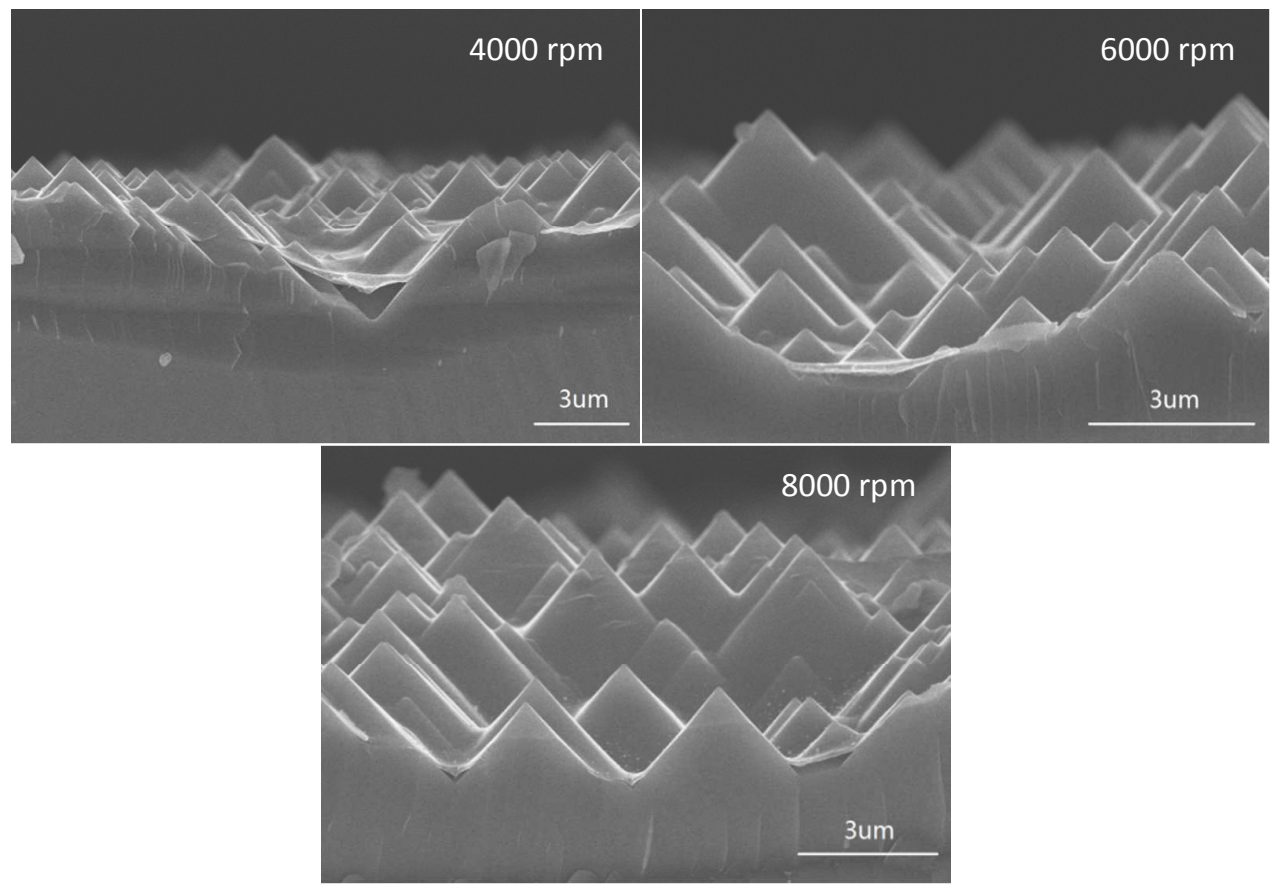

Figure S1 Cross section SEM images of PEDOT:PSS on pyramid in different spin speed (with 0.6 wt.\% of fluorosurfactant)

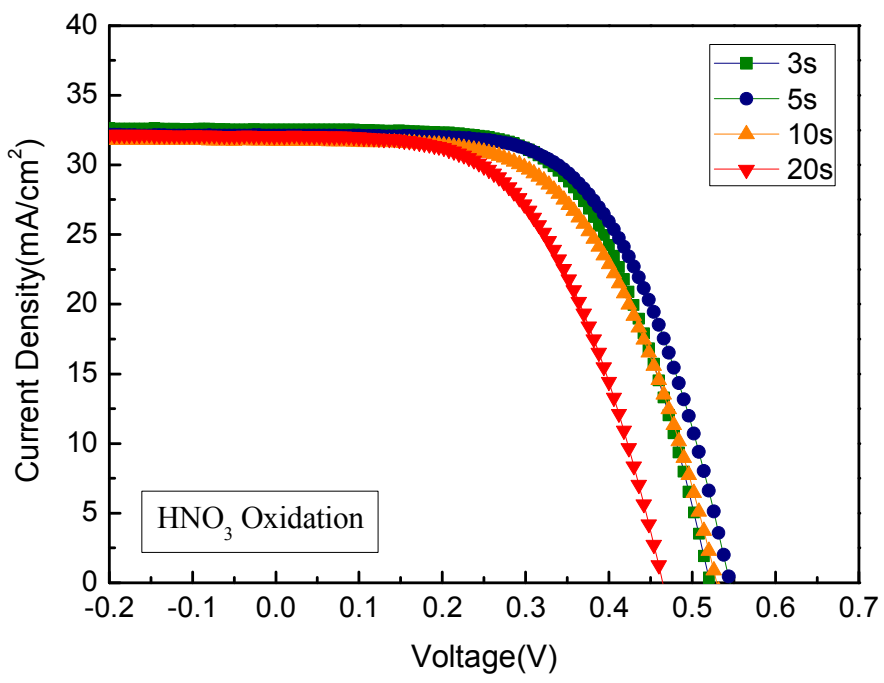

Figure S2 Light J-V curves of the cells with different oxidation time (without amorphous silicon $\mathrm{BSF}$ and $\mathrm{MoO}_{3}$ antireflection layer)

Table S1 Photovoltaic performance of the cells with different oxidation time (without amorphous silicon $\mathrm{BSF}$ and $\mathrm{MoO}_{3}$ antireflection layer)

\begin{tabular}{lllll}
\hline Oxidation time & $\mathrm{Voc}(\mathrm{mV})$ & $\mathrm{Jsc}\left(\mathrm{mA} / \mathrm{cm}^{2}\right)$ & $\mathrm{FF}(\%)$ & Eff.(\%) \\
\hline
\end{tabular}




\begin{tabular}{ccccc}
\hline $\mathrm{HNO}_{3} 3 \mathrm{~s}$ & 520 & 32.52 & 60.06 & 10.16 \\
$\mathrm{HNO}_{3} 5 \mathrm{~s}$ & 544 & 32.04 & 60.04 & 10.46 \\
$\mathrm{HNO}_{3} 10 \mathrm{~s}$ & 532 & 31.73 & 56.59 & 9.55 \\
$\mathrm{HNO}_{3} 20 \mathrm{~s}$ & 466 & 32.03 & 54.36 & 8.11 \\
\hline
\end{tabular}

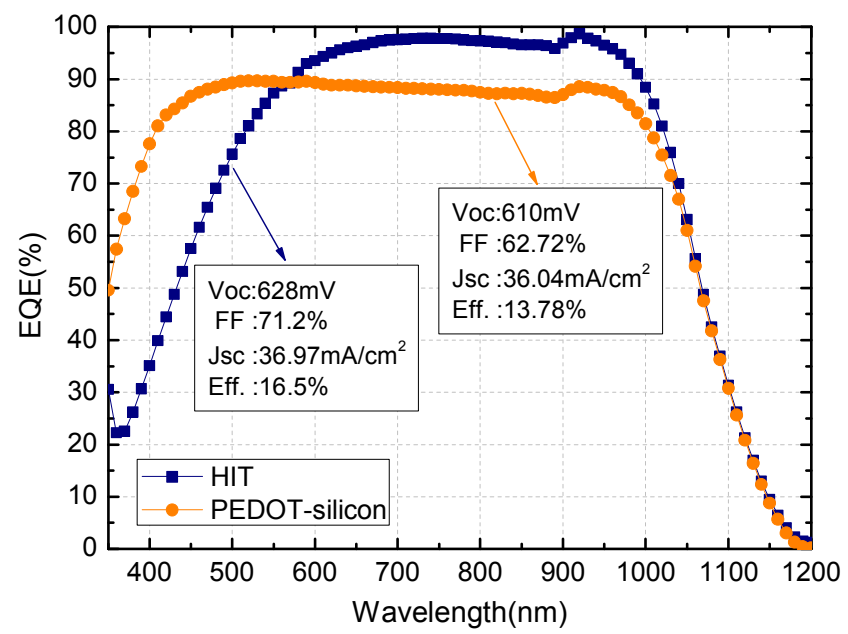

Figure S3 EQE response of our best HIT and PEDOT:PSS-silicon solar cells

Table S2 Minority carrier lifetime of samples at different conditions

\begin{tabular}{ccccccc}
\hline \multirow{2}{*}{ Samples } & $\begin{array}{c}\text { Bare } \\
\text { Si }\end{array}$ & $\begin{array}{c}\text { Bare } \\
\text { Si-AIE }\end{array}$ & $\begin{array}{c}\text { PEDOT- } \\
\mathrm{Si}\end{array}$ & $\begin{array}{c}\text { PEDOT-Si- } \\
\text { AIE }\end{array}$ & $\begin{array}{c}\text { PEDOT-Si-AIE- } \\
\text { BSF }\end{array}$ & $\begin{array}{c}\text { MoO }_{3} \text {-PEDOT- } \\
\text { Si-AIE-BSF }\end{array}$ \\
\hline Lifetime $(\boldsymbol{\mu} \mathbf{s})$ & 4.31 & 6.50 & 10.23 & 15.39 & 34.26 & 150.10 \\
\hline
\end{tabular}

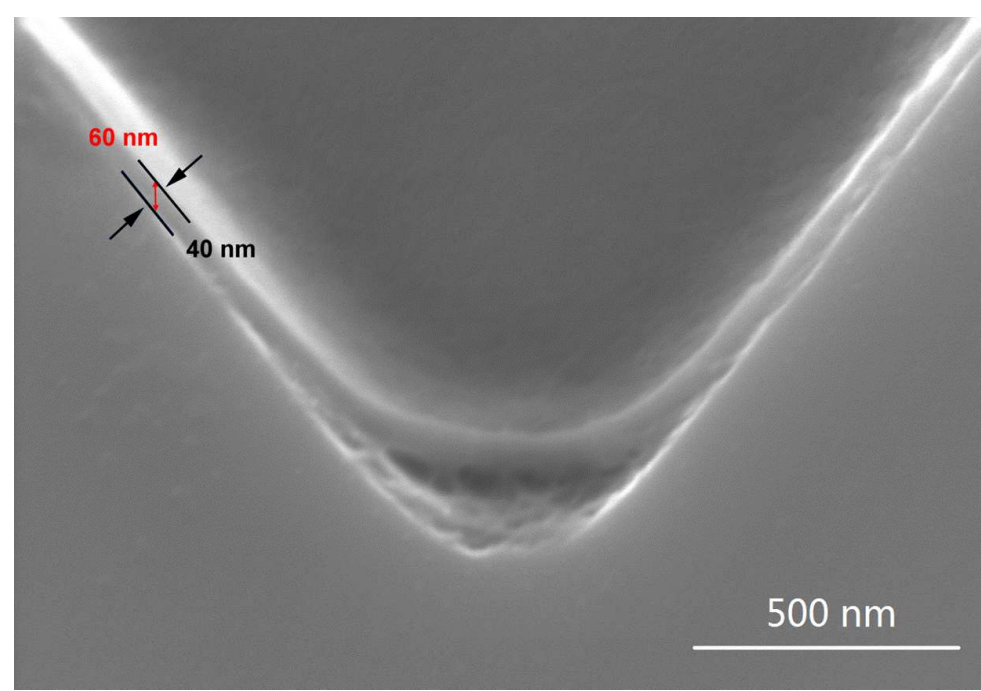

Figure S4 Cross section SEM image of PEDOT:PSS on acid etched silicon substrate 


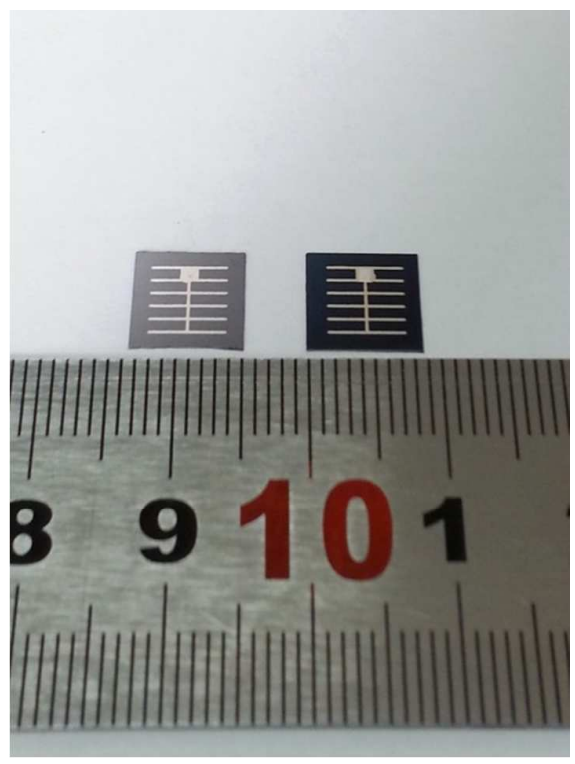

Figure S5 Photographic of the devices with and without $\mathrm{MoO}_{3}$ antireflection layer

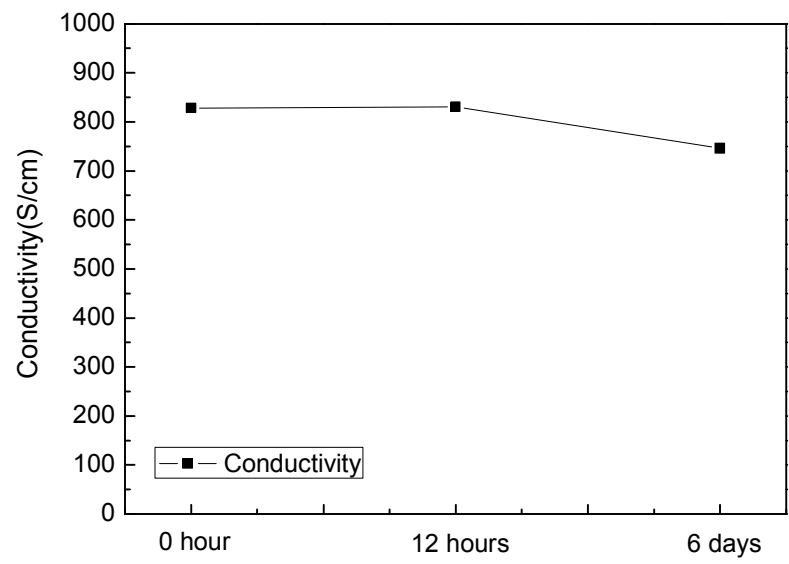

Figure S6 The conductivity decay of PEDOT:PSS on glass storage in air 